\title{
COMPARISON OF SPECTRAL MEASUREMENTS OF MAGNETIC FIELDS IN A SUNSPOT USING LINES WITH DIFFERENT LANDE FACTORS
}

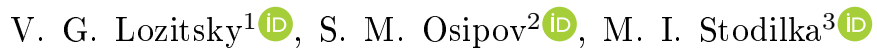 \\ ${ }^{1}$ Astronomical Observatory of the Taras Shevchenko National University of Kyiv, Kyiv, Ukraine \\ ${ }^{2}$ Main Astronomical Observatory of National Academy of Sciences, Kyiv, Ukraine \\ ${ }^{3}$ Astronomical Observatory of Ivan Franko National University of Lviv, Lviv, Ukraine \\ e-mail: lozitskyvv@ukr.net, osipov@mao.kiev.ua, m.stodilka@gmail.com \\ (Received 02 May 2020; accepted 01 July 2020; published online 16 October 2020)
}

\begin{abstract}
We analyze the spectral observations of a sunspot in six metal lines near Fe I $5434.5 \AA$, which have effective Lande factors $g_{\text {eff }}$ from -0.014 to 2.14. The observations were made on August 25, 2015 on the ATsU-5 telescope of GAO NAS of Ukraine, using a circular polarization analyzer and spectra registration with the SBIG ST-8300 CCD camera. The following line parameters are compared: the observed splitting of $I \pm V$ profiles, the width and depth of the Stokes $I$ profiles. Significant differences of the measured magnetic field strengths $B_{\text {obs }}$ were found in separate places of the spot and by lines with different $g_{\text {eff }}$ values. The Fe I $5434.5 \AA$ line $\left(g_{\text {eff }}=-0.014\right)$ shows a measurable splitting in some locations of the sunspot, which corresponds to the magnetic field $B_{\mathrm{obs}} \approx 20 \mathrm{kG}$. Comparison of the widths and depths of the line profiles revealed two special places in the sunspot, where the Fe I $5434.5 \AA$ line was expanded additionally by $\approx 15-35 \%$, whereas other lines with larger Lande factors did not have such a feature. One of the reasons for this expansion could be a sharp and local increase of turbulent velocities, but no active processes such as solar flares or significant Doppler flows were observed at this location. Another reason for this expansion may be the presence of extremely strong and spatially unresolved magnetic fields of mixed magnetic polarity.

Key words: Sun, solar activity, sunspots, spectral analysis, the Zeeman effect, magnetic fields, profiles of spectral lines, superstrong fields.
\end{abstract}

DOI: https://doi.org/10.30970/jps.24.3905

\section{INTRODUTION}

Magnetic fields in sunspots have been measured for more than 100 years (since 1915), and, as a rule, using spectral lines with the largest Lande factors [1]. This provides the highest accuracy of measurements and the ability to determine such an important characteristic as the modulus of the magnetic field strength, and also, regardless of instrumental polarization, the inclination of the field vector to the line of sight and the scattering light. Though, in this case, there are some methodological problems that are encountered when comparing data from different observatories [2]. As for the most mass magnetographic measurements to date, they usually give a longitudinal component of the magnetic field and, moreover, are not corrected for changing the profile of the spectral line due to non-magnetic changes in the transition from the photosphere to the sunspot. As a result, the most reliable measurements of magnetic fields in sunspots today are traditional spectral measurements or modern Stokes diagnostics using realistic models of the solar atmosphere [3]. However, in the latter case, lines with large Lande factors are also commonly used. This automatically limits the range of the magnetic field strengths available for measurements [4]. Regarding direct data for cases corresponding to the filling factor $f$ close to unity (i. e., $f \approx 1$ ), the strongest magnetic fields in the spots were found to be within 5.5-6.1 kG [5-7]. However, sunspots with such superstrong fields are rare; for the most part, the typical magnetic field strength in developed sunspots (with shadow and penumbra) is in the range of $2-3 \mathrm{kG}$.
Subtle effects were found in line profiles which indicate that the magnetic field strength in spatially unresolved elements of sunspots can be $7-8 \mathrm{kG}[8,9]$. The filling factor for such elements can reach values $f=0.2-0.3$, and the Doppler shifts correspond to plasma lifting at the speeds of $2-3 \mathrm{~km} / \mathrm{sec}$ [10]. However, in article [8] the conclusion is different: the substance in the subtelescopic elements goes down with the speed of about $20 \mathrm{~km} / \mathrm{sec}$. A possible reason for the difference between these findings is that in the papers $[9,10]$ the umbra of large spots was studied, whereas in the article [8] - penumbra of sunspots.

It should be noted that the particularly strong magnetic fields in the range of $7-8 \mathrm{kG}$ are, in fact, close to the upper limit of detectable (measurable) fields, when using the spectral lines like Fe I 5250.2 or Fe I 6302.5 with large Lande factors. The mentioned authors analyzed the spectral lines of Fe I 6301.5 and 6302.5 with effective Lande factors 1.67 and 2.50, respectively, which in the case of high magnetic strengths are split so strongly that their Zeeman $\sigma$ components begin to overlap mutually, complicating the diagnosis of thin photometric effects in the adjacent spectral continuum. This is especially true in the sunspot umbra where the numerous and variable molecular blends can occur. That is why it is better to use spectral lines with small Lande factors $\left(g_{\text {eff }} \leq 1\right)$ to measure even stronger magnetic fields.

It is important to note that modern methods of measuring magnetic fields in sunspots are mainly oriented towards observations of fields of regular polarity, which give characteristic manifestations in the Stokes parameters $Q, U$ and $V$. However, for 
spatially unresolved magnetic fields of mixed polarity, the corresponding observed manifestations in these parameters may be close to zero, i. e. not detectable. At the same time, strong mixed-polarity fields can be detected by the Stokes $I$ profile, that is, by the integral intensity, on the basis of the observations of significant expansion of this profile. However, in practice, this parameter is almost never analyzed when interpreting observations.

In this study, we use both of the mentioned methodological factors: spectral lines with very small Lande factors and data on the line profiles in the integral intensity. The purpose of our work is to study the problem of the upper limit of the magnetic field in the sunspot using the spectral data obtained with a circular polarization analyzer.

\section{OBSERVATIONS AND SPECTRAL LINES}

Observational material for our study was obtained with horizontal solar telescope ATsU-5 of Main Astronomical Observatory of the National Academy of Science of Ukraine. The telescope is well tested and has a half-width

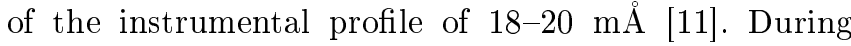
the observations, the spectra of sunspots and surrounding areas were recorded using an SBIG ST-8300 CCD camera. To obtain the spectra $I+V$ and $I-V$, a polarization mosaic was used by Skomorovsky [12] and a quarter-wave plate. Both the polarization mosaic and the quarter-wave plate were placed in front of the entrance slit of the spectrograph at a distance of about $1 \mathrm{~cm}$. Some other features of such observations on ATsU-5 are described in paper by Lozitsky and Osipov [13].

In this paper, we analyze the observations of the tail sunspot in the active region of NOAA 2403, which was located at a distance $\rho / R=0.415, \mu=0.91$ from the center of the disk. The diameter of the penumbra of this spot was about $45 \mathrm{Mm}$; the spot was irregular in shape, especially its umbra (Fig. 1). The exposure of the spectrum of this spot was at the following time: $07^{\mathrm{h}} 36^{\mathrm{m}}-07^{\mathrm{h}} 46^{\mathrm{m}}$ UT. During the exposure, the entrance slit of the spectrograph crossed the spot in the northsouth direction on the disk, as it is shown in Fig. 1.

When using the polarization mosaic and the $\lambda / 4$ plate before the entrance slit of the spectrograph, the positive thing is that the propagation of rays inside the spectrograph is not disturbed and therefore the results of careful studies of the instrument [11] remain valid. Therefore, we used a standard procedure of observation: a flatfield pattern was calculated from the series of records in quiet areas around the spot, the scattered light in the spectrograph was determined from the signal determination above and under the recorded spectrum. However, the disadvantage here is that the obtained spectra of $I+V$ and $I-V$ refer to different locations in the Sun, which in this case have a discrete step of 3.3 Mm. That is, in order to measure the Zeeman splitting, one has to compare the positions in the spectrum of orthogonally polarized $\sigma$ components not for the same

\begin{tabular}{|c|l|c|c|c|}
\hline No. & Element, multiplet & $\lambda, \AA$ & $\mathrm{EP}, \mathrm{eV}$ & $g_{\text {eff }}$ \\
\hline 1 & Mn I - 1 & 5432.548 & 0.00 & 2.143 \\
\hline 2 & Fe I - 1143 & 5432.950 & 4.43 & 0.666 \\
\hline 3 & Fe I - 15 & 5434.527 & 1.01 & -0.014 \\
\hline 4 & Ni I - 70 & 5435.871 & 1.98 & 0.500 \\
\hline 5 & Fe I - 1161 & 5436.299 & 4.37 & 1.440 \\
\hline 6 & Fe I - 113 & 5436.594 & 2.27 & 1.816 \\
\hline
\end{tabular}

Table 1. Selected magnetosensitive lines which were used for magnetic field measurements in the sunspot

location on the Sun, but for neighboring ones spaced 3.3 Mm apart. As different locations in the Sun may have not only different Zeeman splittings $\Delta \lambda_{\mathrm{H}}$ but also Doppler shifts $\Delta \lambda_{\mathrm{E}}$ due to the Evershed effect, the measured magnetic splitting found in this way can have significant errors, especially for spots near the solar limb. To reduce these errors, the spectra of the same location on the Sun were recorded twice, with different orientations of the quarter-wave plate, which differed by $90^{\circ}$.

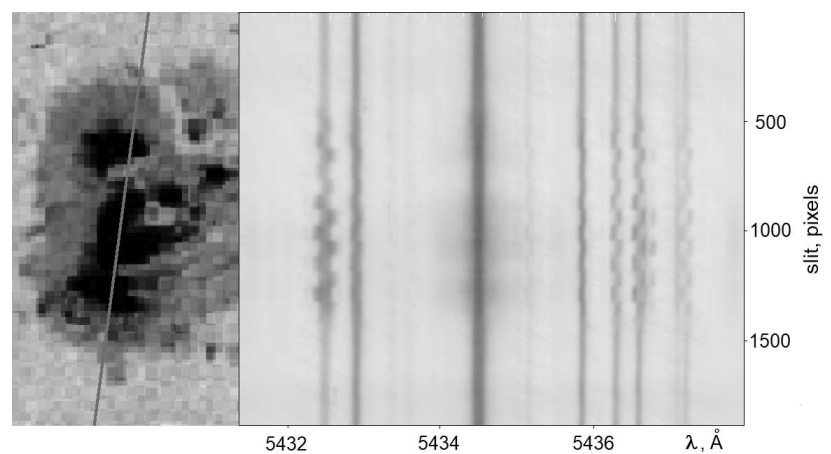

Fig. 1. The sunspot under study in white light according to the SOHO data (left) and the spectrum obtained with the ATsU-5, which is analyzed in this paper (right)

Then, if at the first position of a quarter-wave plate (which, for example, corresponds to the angle $+45^{\circ}$ relative to the optical axes of the mosaic), the difference of the spectral line positions in the two adjacent mosaic strips was $2 \Delta \lambda_{\mathrm{H}}+\Delta \lambda_{\mathrm{E}}$, then at the angle of $-45^{\circ}$ it will already be $2 \Delta \lambda_{\mathrm{H}}-\Delta \lambda_{\mathrm{E}}$. Taking the average of these two values, we get only $2 \Delta \lambda_{\mathrm{H}}$, and according to it the correct value of the magnetic field $B$.

$I \pm V$ spectra were recorded in the wavelength range about $\pm 4 \AA$ around Fe I $5434.5 \AA$ line. The list of the suitable spectral lines, which are placed in this range, is presented in Table 1. In this Table, Lande factors for lines Nos. 3 and 5-6 correspond to empirically determined values according to [14]; for other lines, these factors are theoretical for the case of $L S$ coupling. Other parameters of the spectral lines are taken from the multiplet tables by Moore [15]. 


\section{MAGNETIC FIELDS}

Magnetic field measurements were carried out by the method of "centers of gravity" of $I+V$ and $I-V$ profiles. The difference between the positions of these profiles in a spectrum was considered to be $2 \Delta \lambda_{\mathrm{H}}$, i. e. double Zeeman splitting. It is necessary to note that it is correct for a pure longitudinal field only when angle $\gamma$ between the field line and the line of sight is $0^{\circ}$ or $180^{\circ}$. In other cases, measured splitting should be smaller than the true one, and the determined magnetic field strength is expected to be reduced in comparison with the actual magnetic field value. In order to reduce the influence of noise fluctuations in far wings of the lines, only central parts of the profiles were taken into account where distances from the line center did not exceed the half-width of the spectral line.

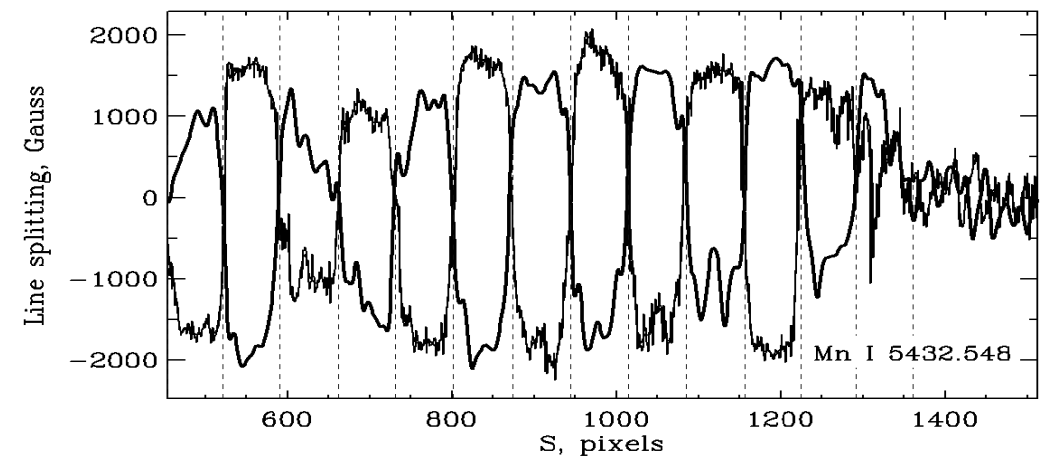

Fig. 2. Distribution of splitting for line No. 1 ( Mn I 5432.548, $g_{\mathrm{eff}}=2.143$ ) along the direction of the entrance slit of the spectrograph. The borders of the bands of the polarization mosaic are shown by vertical stroke lines. For each band of the polarization mosaic, the value of the "center of gravity" of the line is shown for two orientations of quarter-wave plate, $+45^{\circ}$ and $-45^{\circ}$

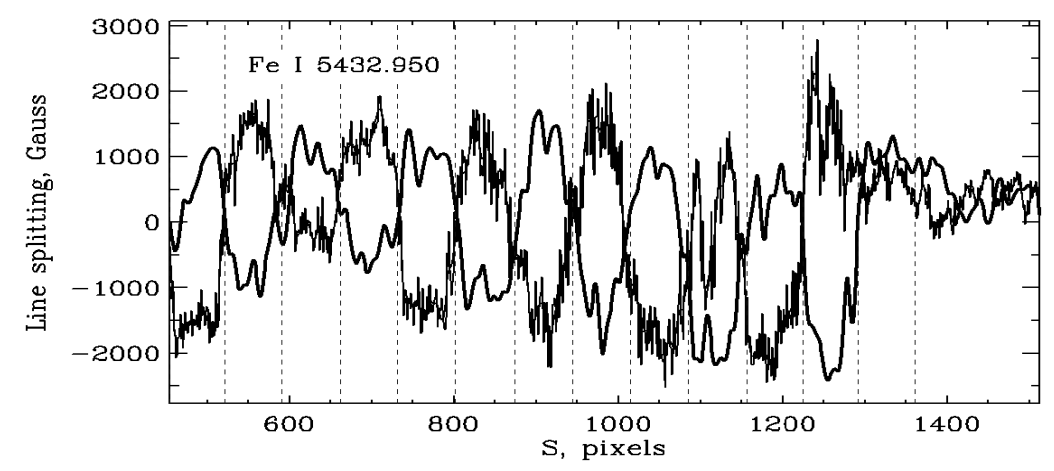

Fig. 3. The same as in Fig. 2 but for line No. 2 (Fe I 5432.950, $g_{\text {eff }}=0.666$ )

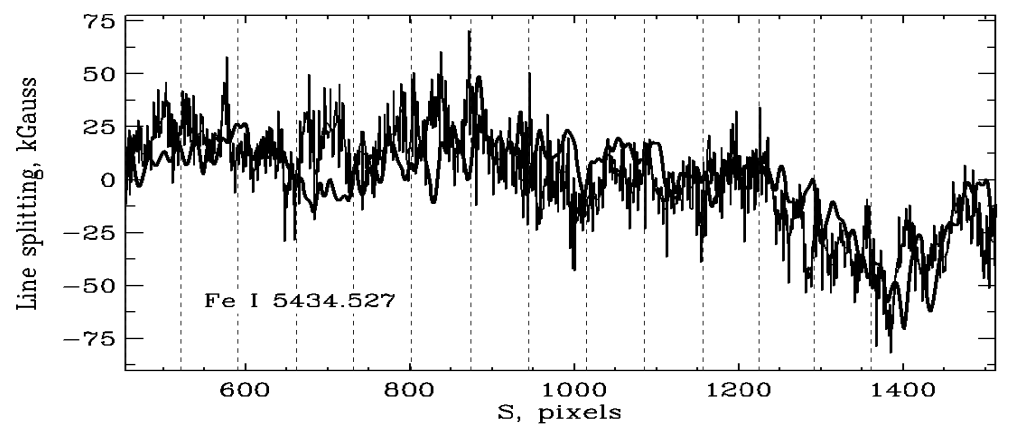

Fig. 4. The same as in Figs. 2 and 3 but for line No. 3 (Fe I 5434.527, $g_{\mathrm{eff}}=-0.014$ )

Figures 2 and 3 show, for illustration, the distribution of spectral positions of lines Nos. 1 and 2 (from the list of Table 1) along the direction of the entrance slit of the spectrograph for two orientations of the quarterwave plate. These spectral positions are calibrated in gauss $(\mathrm{G})$ on the ordinate axis and presented by two curves which correspond to angles $+45^{\circ}$ and $-45^{\circ}$ relative to the optical axis of the polarization mosaic. Along the horizontal axis in the Figures, the horizontal coordinates of the corresponding places on the Sun are given 
in the numbers of pixels (slit, pxl). We will denote this parameter in the short form, as $S$ below.

One can see the following main well-visible effects: (a) periodical deviations of the line position when transiting from a given band of mosaic to the next, and (b) discrete change of the sign of deviation to the opposite one for different orientations of the quarter-wave plate. In particular, such effects demonstrate the magnetic nature of these manifestations.

In order to determine the magnitude of the measured magnetic field according to these graphs, it is necessary to take half the difference of the position of the line with a different orientation of the quarter-wave plate for each specific strip of the mosaic. For example, in Fig. 2 in the abscissa interval $S=800-870$ the line positions correspond to values of $+1800 \mathrm{G}$ and $-2000 \mathrm{G}$. Subtracting the second value from the first and taking half, we have an average field in this strip equal to $1900 \mathrm{G}$. In the physical sense, this value is intermediate between the longitudinal component $B_{\|}=B \cos \gamma$ and the modulus of the magnetic field $B$, since the observed splitting of the Zeeman $\pi$ and $\sigma$ components is not complete (this is clearly seen in Fig. 1). That is, it can be expected that in some places in the spot, the modulus of the magnetic field was greater than $\approx 2 \mathrm{kG}$.

In addition, as can be seen from Figs. 2 and 3, the characteristic magnitude of the sharp oscillations of the magnetic field in the spot is clearly smaller than the equivalent width of the mosaic strip, i.e. $3.3 \mathrm{Mm}$. In Fig. 3, this follows from the observed effects in the abscissa interval $S=1080-1160$, where the characteristic "two-tops" picture of the observed splitting in this strip is repeated at both positions of $\lambda / 4$ plate.

Another interesting effect is obvious from the consideration of these drawings, namely that the magnitude of the magnetic field may differ significantly in different spectral lines. For example, in the interval of $S=1220-1290$, the magnitude of the magnetic field with line No. 1 equals 1200 G, whereas with line No. 2 (which has a much smaller Lande factor) - up to $2200 \mathrm{G}$. However, in other places of the sunspot, these differences are smaller, generally within the range of 300-500 G.

A similar examination of the observational data for line No. 3 with the very small Lande factor $(-0.014)$ shows that in some places of the sunspot it also has similar evidence of the Zeeman splitting (Fig. 4).

For example, this is seen in the abscissa intervals 670720 and $820-830$, where, at different positions of the plate $\lambda / 4$, the "center of gravity" of the line deviates in opposite directions relative to the direction of the spectral dispersion. If this is interpreted as a manifestation of the Zeeman effect, then the corresponding magnetic field should be at the level of $\approx 20 \mathrm{kG}$. Another conclusion follows from Fig. 4: the corresponding places in the sunspot with particularly strong fields are quite local, with a typical scale, probably $1-3 \mathrm{Mm}$. This is consistent with the characteristics of the extremely strong magnetic fields of $\sim 10^{4} \mathrm{G}$ found previously for solar flares [16].

\section{PECULIARITIES OF STOKES $I$}

As was pointed out above, Stokes $I$ profile (integral intensity) is an important parameter for the case when the magnetic field is very tangled, e.g. in the form of spatially unresolved discrete structures of opposite magnetic polarity. If these magnetic polarities have approximately equal magnetic flux, observed Stokes $Q$, $U$ and $V$ parameters should be close to zero in the whole wavelength range of the spectral magneto-sensitive line. That means that such mixed-polarity magnetic fields will not give specific spectral manifestations, which is typical of the Zeeman effect. On the other hand, the presence of such magnetic fields can be discovered using the Hanle effect [17]. However, this effect has essential limitation, namely, it is suitable for the measurements of magnetic fields with strength no more than $\sim 10^{2} \mathrm{G}$. That is, this effect is useless in the magnetic field diagnostics for strength range $\geq 10^{3} \mathrm{G}$.
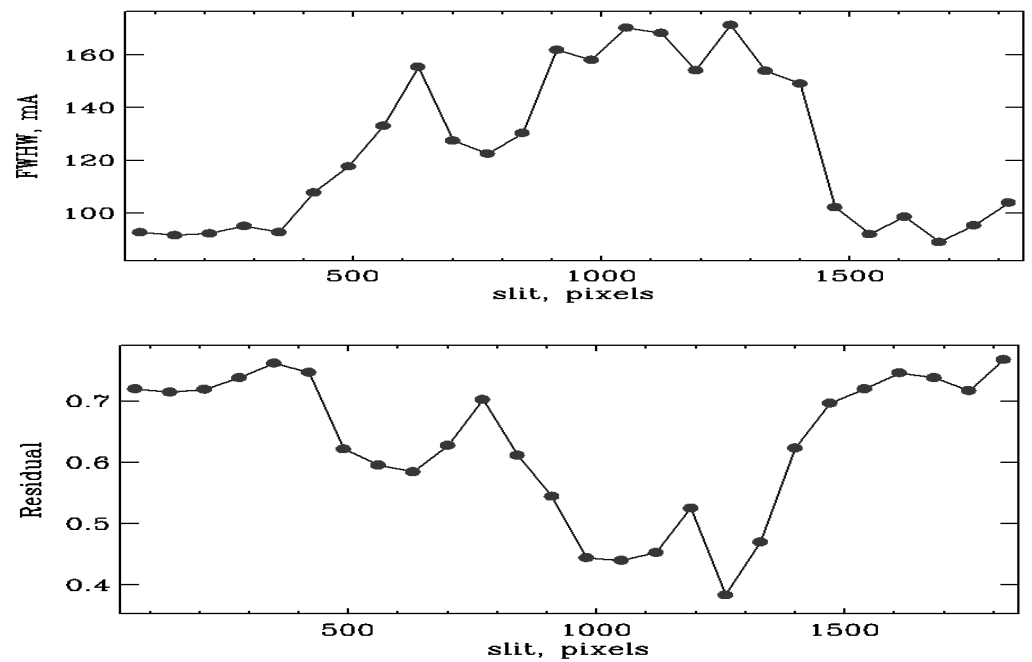

Fig. 5. Comparison for Mn I 5432.548 ( $g_{\text {eff }}=2.143$ ) of the half-width of the Stokes profile $I$ (upper graph) with the central residual intensity (lower graph) for the same places of the studied spot for line No. 1 
However, such strong "tangled" magnetic fields can be detected using the Zeeman effect on the basis of Stokes $I$ analysis. A strong magnetic field should expand Stokes $I$ profile in both cases, namely, if this field has the same (regular) polarity and if this field has mixed polarities. Theoretically, close contact of opposite magnetic polarities is expected to be in many-lamellar structures like magnetic vortexes, which may have a very strong magnetic field of $\sim 10^{4} \mathrm{G}$ range [18]. In this case, it is important to study, in particular, Stokes $I$ profiles from our observations.

Figures 5 and 6 represent the observed half-widths of the Stokes $I$ profiles and the central residual intensity for spectral lines Nos. 1 and 3, which have very different Lande factors. One can see that Mn I 5432.548 line with a large Lande factor $\left(g_{\text {eff }}=2.143\right)$ has strong expanding for the transition from photosphere to the sunspot umbra, its half-width grows from $\approx 90 \mathrm{m \AA}$ outside the sunspot to $\approx 170 \mathrm{~m} \AA$ in the sunspot umbra. Notice, on a large interval of the umbra section where intensities in the spectral continuum are minimal $(S \approx 900 \div 1300)$, the change of the half-width of the line is relatively negligible. At the border of the umbra and penumbra of the sunspot $(S \approx 500)$, this line is slightly expanded. As for the central residual intensity, it is minimal in the spot core.
Line No. 3 behaves differently. It has two "jumps" in half-width, one of them at $S \approx 500$ being at the "umbrapenumbra" border of the sunspot, and the other at $S \approx$ 1260 , at the sunspot umbra. In the first mentioned place, the central residual intensity of this line is not extreme, while in the other place this parameter is close to the minimum over the entire cross section of the spot.

Obviously, the main factor of expansion of the first spectral line is the magnetic field, i. e. the Zeeman splitting, which should be maximal in the umbra of the sunspot. Let us estimate the influence of this effect taking into account that for this line the relation between the Zeeman splitting $\Delta \lambda_{\mathrm{H}}$ and the magnetic field $B$ is as follows:

$$
\Delta \lambda_{\mathrm{H}}=2.95 \times 10^{-5} B
$$

where $\Delta \lambda_{\mathrm{H}}$ is expressed in angstroms $(\AA)$, and the magnetic field $B$ in gauss $(\mathrm{G})$.

For the magnetic field of $B=2000 \mathrm{G}$ we have $\Delta \lambda_{\mathrm{H}}=$ $59 \mathrm{~m} \AA, 2 \Delta \lambda_{\mathrm{H}}=118 \mathrm{~m} \AA$. Since the width of this line outside the spot is about $90 \mathrm{~m} \AA$, the expected full width of this line in the spot is $\Delta \lambda_{1 / 2, \exp } \approx\left(90^{2}+118^{2}\right)^{1 / 2} \approx$ $148(\mathrm{~m} \AA)$. Note that such an estimate is valid if the unperturbed line profiles and the line profile extended by the Zeeman splitting can be approximated by Gaussians.
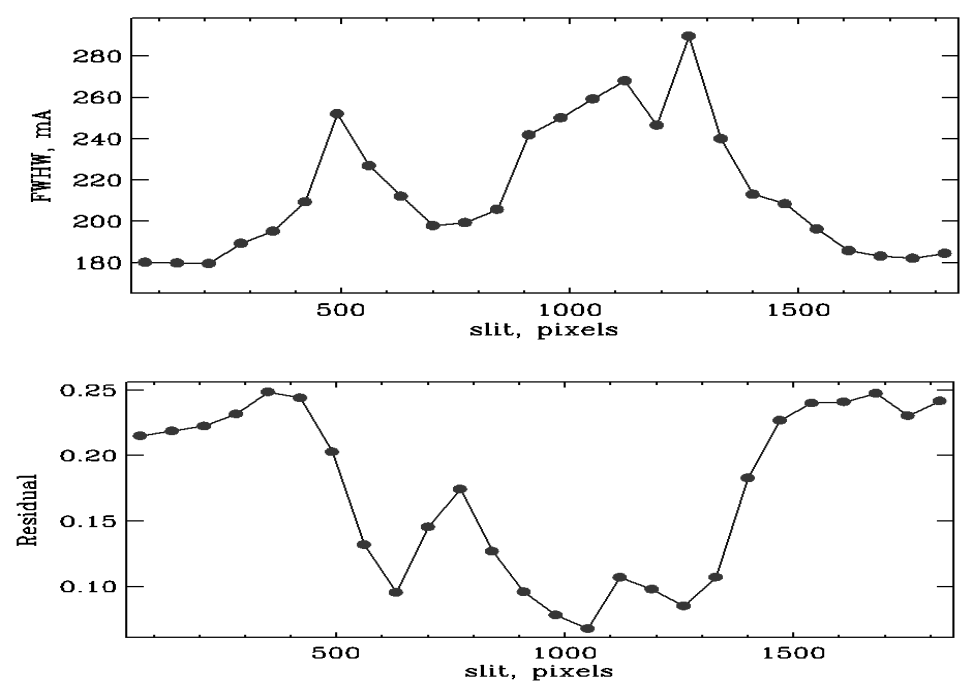

Fig. 6. Comparison of Fe I 5434.527 ( $\left.g_{\mathrm{eff}}=-0.014\right)$ of the half-width of the Stokes profile $I$ (upper graph) with the central residual intensity (lower graph) for the same places of the studied spot for line No. 3

As we can see, in this case, the profile expands by $64 \%$ rather than $\approx 89 \%$, as the observations show. However, the magnitude of the magnetic field $B=2000 \mathrm{G}$ is somewhat conditional. From our direct observations (see Fig. 2 above), we determine the value close to the longitudinal component of the field $B_{\|}$, since we do not observe here a complete spectral separation of the Zeeman $\pi$ - and $\sigma$-components. Therefore, assuming that $B=2500 \mathrm{G}$, we already have $2 \Delta \lambda_{\mathrm{H}}=147.5 \mathrm{m \AA}$, and the expected half-width $\Delta \lambda_{1 / 2, \exp } \approx\left(90^{2}+147.5^{2}\right)^{1 / 2} \approx$ $173 \mathrm{~m} \AA$, in good agreement with the observations.

That is, in this case, we have fully explained if not all the observed extension of this line, then at least a large part of it. It is obvious that some part of the extension of the line is also due to non-magnetic factors, in particular due to a significant increase in the absorption coefficient in the spot, which is evident from the fact that the equivalent width of the line is very noticeable here. Recall that the well-known magnetic amplification of magnetically sensitive lines [19] should reach theoretically $30 \%$ and be observed only for non-longitudinal magnetic fields (theoretical maximum of this effect is at $\gamma \approx 55^{\circ}$ ). That is, in general, the effect observed in line No. 1 may well be explained by a certain combination of magnetic and non-magnetic expansion factors. 

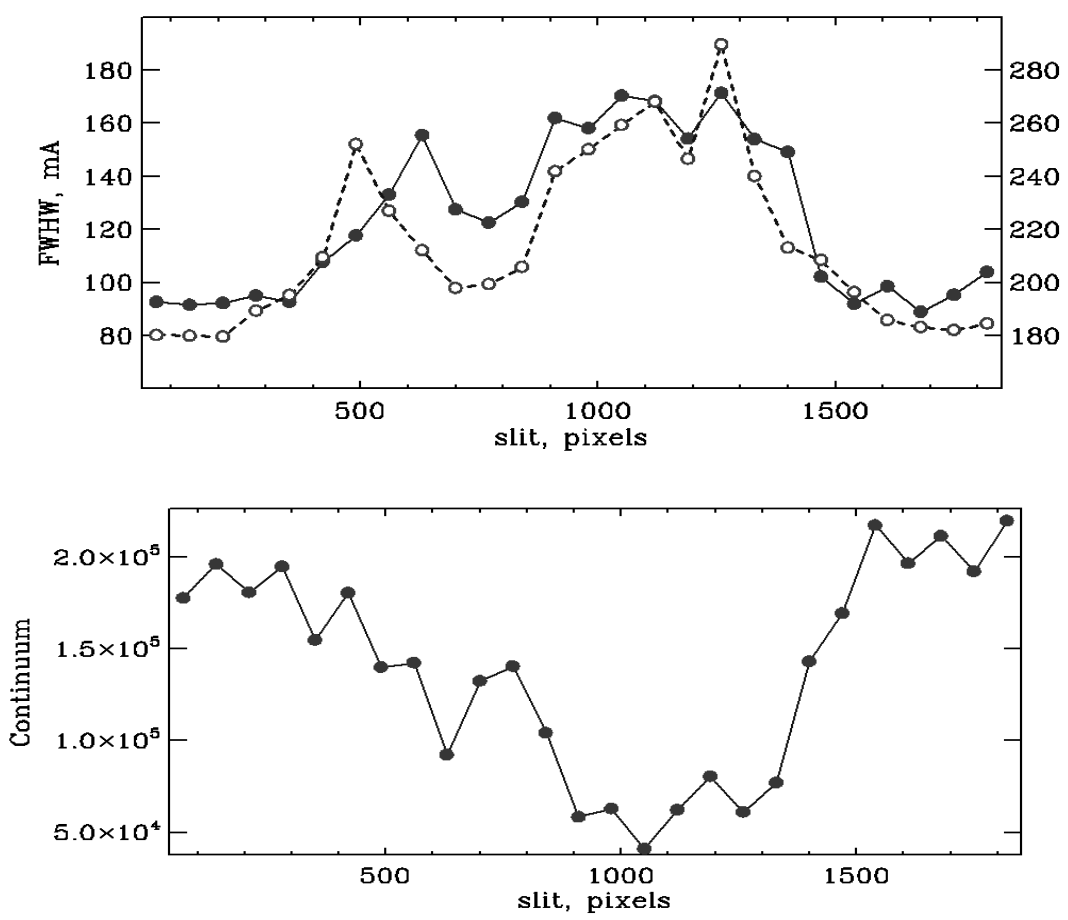

Fig. 7. Comparison of the half-width of the Stokes profile $I$ on upper graph with the continuum intensity on lower graph for lines No. 1 (solid line) and No. 3 (dashed)

Line No. 3 (Fe I $5434.527 \AA$, $g_{\text {eff }}=-0.014$ ), behaves differently in comparison with line No. 1 (Figs. 6 and $7)$. One can see from these Figures that at $S \approx 500$ and 1260 a sharp increase in the line width by $30-50$ $\mathrm{m} \AA$ was observed. This seems strange because at this place the intensity in the continuum (and therefore the temperature) is about the same as at other places of the sunspot (Fig. 7). The elementary estimate according to the scheme as above for line No. 1 shows that the magnetic field of the $2500 \mathrm{G}$ could increase the line width by only a few thousandth $m \AA$, which is not enough.

As for the central residual intensity, it changes in line No. 3 less significantly (Fig. 6). In particular, we do not see any special effects at $S \approx 500$ and 1260 , as in the case of the width of this line.

Therefore, there are two possible alternatives for the Fe I 5434.527 A line: either (a) it is a purely non-magnetic line extension, probably by turbulent velocities with high gradients of model parameters, or (b) an expansion by much stronger magnetic fields. In principle, some combination of these effects (a) $+(\mathrm{b})$ is possible.

With respect to turbulent velocities, this assumption seems doubtful, since no active processes were observed at these places ( $S \approx 500$ and 1260 ), such as a solar flare or high beam velocities. Therefore, let us try to estimate what magnetic field is necessary for this line to increase its width to the observed value.

For this purpose, suppose that the true non-magnetic half-width of the Fe I $5434.527 \AA$ line at the point $S \approx$ 500 is approximately $200 \mathrm{~m} \AA$, as can be seen from a comparison of this point with neighboring places $S \approx 400$ and 700 (Figs. 6 and 7 ). However, at the point $S \approx 500$ we observe a sharp jump in the half-width of the line, where in fact this parameter is equal to $270 \mathrm{~m} \AA$. We pose the question this way: what magnetic field value is needed to increase the line half-width from $200 \mathrm{~m} \AA$ to $270 \mathrm{~m} \AA$ ?

For the Fe I $5434.527 \AA$ line, the calibration formula for linking the parameters $\Delta \lambda_{\mathrm{H}}$ and $B$ is as follows:

$$
\Delta \lambda_{\mathrm{H}}=1.93 \times 10^{-7} B
$$

Given this formula, it is easy to get an expression to estimate the required magnetic field:

$$
B=0.5\left[\left(\Delta \lambda_{1 / 2, \text { jump }}\right)^{2}-\left(\Delta \lambda_{1 / 2, \text { spot }}\right)^{2}\right]^{1 / 2} / 1.93 \times 10^{-7},
$$

where $\Delta \lambda_{1 / 2, \text { jump }} \approx 0.27 \AA$ is the observed half-width

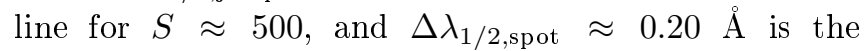
same parameter for neighboring places of the sunspot. Substituting these values, we obtain $B \approx 4.7 \times 10^{5}$ G. Observational evidences for magnetic fields of the same order was obtained previously for solar flares [20]. However, for solar flares, not Stokes $I$ profiles but $I \pm V$ profiles were analyzed.

\section{CONCLUSIONS AND DISCUSSION}

The main conclusion of our study is that in the tail sunspot of the active region of NOAA 2403 there were probably extremely strong magnetic fields of $\sim 10^{4} \mathrm{G}$, 
at a time when there were no solar flares in this region. This is indicated by the characteristic effects in the $I \pm V$ profiles of the Fe I $5434.5 \AA$ line, which has a very small Lande factor $\left(g_{\text {eff }}=-0.014\right)$, determined empirically under laboratory conditions. A comparison of the half widths of the Stokes $I$ profiles of the six spectral lines with different Lande factors $(-0.014$ to 2.14$)$ revealed two special places in the sunspot where the Fe I 5434.5 line was expanded further by $\approx 15-35 \%$, whereas other lines with larger Lande factors did not have a similar feature. One of the reasons for this expansion could be a sharp and local increase of turbulent velocities, but no active processes such as solar flares or significant Doppler velocities were observed at this location. Another reason for this expansion could be the presence of superstrong $\left(\sim 10^{5} \mathrm{G}\right)$ and spatially unresolved magnetic fields of mixed magnetic polarity.

It should be recalled that for the first time, magnetic fields with the intensity of $\sim 10^{4} \mathrm{G}$ in sunspots were assumed by A. B. Severny [21]. He wrote: "Thus, it is quite possible that the magnetic field inside the spots has a fine structure, the averaging of which during observations leads to fields of $\sim 10^{3}$ gauss, while the actual field of individual elements of the spot (possibly of different polarity and slope) is tens of thousands of gauss; i. e., the situation can be the same as in the case of granulation, where averaging of individual fields ( $\sim 100$ gauss $)$ of granules in the instrument leads to fields of the order of several gauss. If this assumption is justified (as a result of further studies) and the fields in the spots reach $\sim 50000$ gauss, being concentrated in small tubes, then the problem of the particle acceleration can find its more or less simple solution. In this case, the plasma in the region between the tubes will be extremely diamagnetic and its ejections with high velocities are possible."

In fact, it was a heuristic conjecture since any concrete arguments were not presented. True, Severny [21] mentioned as an argument for this topic the effect of strengthening of the spectral line wings in sunspots. However, the authors of the present work do not know any publications where this effect was considered in detail. Moreover, wings of magneto-sensitive lines in sunspots can be strengthened due to such non-magnetic effects as the growth of the dampfing constant and the absorption coefficient and not a magnetic field.

In our study, we present more direct arguments in favor of the reality of such superstrong magnetic fields, which are based on the consideration of several spectral lines with different Lande factors including Fe I $5434.5 \AA$ with very low magnetic sensitivity. We show for the first time that this line can increase its half-width by 15 $35 \%$ in the sunspots, and this increase cannot be caused by temperature. Two alternatives are possible regarding this phenomenon: a sufficient increasing of turbulent velocities or the presence of super-strong magnetic fields $\left(\sim 10^{5} \mathrm{G}\right)$. If we reject the second alternative, then it is necessary to explain why in a "quiet" sunspot (without solar flares), the sharp increase in turbulent velocities can occur when the temperature there is the same as in the nearest places of the sunspot umbra.

In the future, we plan to assess more specifically the effects of turbulence in the spot by constructing a semiempirical model using the Tikhonov stabilizers [22] to ensure the stability of the solution. At the same time, the height of the layer, which has high turbulence, can also be determined. It would be interesting to compare this consideration with the results for the areas of solar flares, which was previously done in the work by Lozitsky and Stodilka [23].

Acknowledgements. This study was funded by the Taras Shevchenko National University of Kyiv, project No.19БФ023-03, by Main Astronomical Observatory of National Academy of Sciences of Ukraine, project No. 352B, and by Ivan Vranko National University of L'viv, project No. AO91- $\Phi$.
[1] G. E. Hale, F. Ellerman, S. B. Nicholson, A. H. Joy, Astrophys. J. 49, 153 (1919); https://doi.org/10.108 $6 / 142452$.

[2] N. I. Lozitska et al., Adv. Space Res. 55, 897 (2015); https://doi.org/10.1016/j.asr.2014.08.006.

[3] B. Ruiz Cobo, J. C. del Toro Iniesta, Astrophys. J. 398, 375 (1992); https://doi.org/10.1086/171862.

[4] V. G. Lozitsky, Adv. Space Res. 55, 958 (2015); https : //doi.org/10.1016/j.asr.2014.09.028.

[5] W. Livingston, J. W. Harvey, O. V. Malanushenko, Solar Phys. 239, 41 (2006); https://doi.org/10.1007/s112 07-006-0265-4.

[6] Y. Wang et al., Res. Not. Amer. Astron. Soc. 2, No.1, 8 (2018); https://doi.org/10.3847/2515-5172/aaa670.

[7] V. G. Lozitsky, V. B. Yurchyshyn, K. Ahn, H. Wang, N. I. Lozitska, Odessa Astron. Publ. 30, 152 (2018); https : //doi.org/10.18524/1810-4215.2018.31.144560.

[8] M. Van Noort, A. Lagg, S. K. Tiwari, S. K. Solanki,
Astron. Astrophys. 557, A24 (2013); https://doi.org/ 10.1051/0004-6361/201321073.

[9] V. G. Lozitsky, Adv. Space Res. 57, 398 (2016); https: //doi.org/10.1016/j.asr. 2015.08.032.

[10] V. G. Lozitsky, Adv. Space Res. 59, 1416 (2017); https: //doi.org/10.1016/j.asr. 2016.11.034.

[11] S. N. Osipov, Kinem. Phys. Celest. Bodies 31, 261 (2015); https://doi.org/10.3103/S088459131505008 6.

[12] V. I. Skomorovsky, Issled. Geomagn. Aeronom. i Fiz. Soln. 26, 220 (1974).

[13] V. Lozitsky, S. Osipov, Bull. Taras Shevchenko Natl. Univ. Kyiv 55, 34 (2017);

[14] E. N. Zemanek, A. P. Stefanov, Bull. Kyiv Univ. Astron. 18, 20 (1976).

[15] C. E. Moore, Contrib. Princeton Univ. Observ. 20, 1 (1945).

[16] V. G. Lozitsky, Kinem. Phys. Celest. Bodies 14, 401 
(1998).

[17] J. Trujillo Bueno, N. Shchukina, A. Asensio Ramos, Nature 404, 326 (2004); https://doi.org/10.1038/na ture02669.

[18] A. A. Solov'ev, Solar Phys. 286, 441 (2013); https:// doi .org/10.1007/s11207-013-0284-x.

[19] W. Unno, Publs. Astron. Soc. Jpn. 8, 108 (1956).
[20] V. G. Lozitsky, J. Phys. Stud. 13, 2903 (2009); https: //doi.org/10.30970/jps.13.2903.

[21] A. B. Severny, Astron. Zh. 34, 684 (1957).

[22] M. I. Stodilka, Kinem. Fiz. Nebesn. Tel 19, 334 (2003).

[23] V. G. Lozitsky, M. I. Stodilka, J. Phys. Stud. 23, 4902 (2019); https://doi.org/10.30970/jps.23. 4902.

\title{
ПОРІВНЯННЯ СПЕКТРАЛЬНИХ ВИМІРЮВАНЬ МАГНІТНОГО ПОЛЯ В СОНЯЧНІЙ ПЛЯМІ ПО ЛІНІЯХ ІЗ РІЗНИМИ ФАКТОРАМИ ЛАНДЕ
}

\author{
В. Г. Лозицький ${ }^{1}$, С. М. Осіпов ${ }^{2}$, М. І. Стоділка ${ }^{3}$ \\ ${ }^{1}$ Астрономічна обсерваторія Київсъкого начіоналъного університету імені Тараса Шевченка, Киӥв, Украӥна, \\ ${ }^{2}$ Головна Астрономічна обсерваторіл НАН Украӥни, Київ, Украӥна, \\ ${ }^{3}$ Астрономічна обсерваторіл Лъвівсъкого начіоналъного університету імені Івана Франка, Лъвів, Украӥна, \\ e-mails: lozitsky_v@ukr.net, osipov@mao.kiev.ua,m.stodilka@gmail.com
}

Ми аналізуємо спектрально-поляризаційні спостереження сонячної плями в шести лініях металів поблизу Fe I $5434.5 \AA$, що мають ефективні фактори Ланде geff від -0.014 до 2.14. Спостереження виконали 25 серпня 2015 р. на телескопі АЦУ-5 ГАО НАН України, використовуючи аналізатор кругової поляризації, а також реєстрацію спектрів за допомогою ПЗ3-камери SBIG ST-8300. Зіставлено такі параметри ліній: видиме розщеплення профілів $I \pm V$, а також ширина і глибина профілів Стокса $I$. Виявлено суттєві відмінності виміряних напруженостей $B_{\text {obs }}$ в окремих місцях плями й по лініях із різними величинами $\mathrm{g}_{\mathrm{eff}}$. Лінія Fe I 5434.5 $\AA$ ( $\left.\mathrm{g}_{\mathrm{eff}}=-0.014\right)$ у деяких місцях сонячної плями виявляє достовірне розщеплення, яке відповідає магнітним полям $B_{\text {obs }} \approx 20$ кГс. Зіставлення півширин і глибин профілів ліній показало особливе місце в тіні сонячної плями, де лінія $\mathrm{Fe} I$ $5434.5 \AA$ розширена додатково на $\approx 15 \%$, тоді як інші лінії з більшими факторами Ланде подібної особливості не виявляють. Однією з причин такого розширення могло бути різке й локальне збільшення турбулентних швидкостей, однак у цьому місці не спостерігалось якихось активних процесів типу сонячних спалахів або значних променевих швидкостей. Ще однією причиною такого розширення могла бути наявність особливо сильних і просторово нероздільних магнітних полів змішаної магнітної полярності.

Ключові слова: Сонце, сонячна активність, сонячні плями, спектральний аналіз, ефект Зеємана, магнітні поля, ширини профілів ліній, надсильні магнітні поля. 